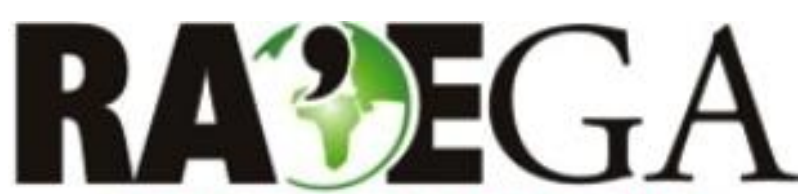

O ESPAÇO GEOGRÁFICO EM ANÁLISE

\title{
ILHAS DE CALOR URBANAS E CONFORTO TÉRMICO HUMANO EM CIDADES DE PORTE MÉDIO: ESTUDO APLICADO EM JUIZ DE FORA (MG)
}

\section{URBAN HEAT ISLANDS AND HUMAN THERMAL COMFORT IN MEDIUM-SIZED CITIES: STUDY APPLIED IN JUIZ DE FORA (MG)}

\author{
Christian Ricardo Ribeiro ${ }^{1}$, Alec Ponte Gonçalves ${ }^{2}$, Fabrício Pires Bastos ${ }^{3}$
}

\section{RESUMO}

\begin{abstract}
A pesquisa baseou-se na proposta teórico-metodológica de Monteiro (1976) para o estudo do Sistema Clima Urbano em Juiz de Fora, cidade que conheceu um intenso processo de crescimento demográfico e de expansão urbana nas últimas décadas. O foco da pesquisa é o subsistema termodinâmico, cujo canal de percepção inclui a investigação a respeito das ilhas de calor urbanas. A coleta de dados de temperatura e de umidade relativa do ar foi realizada através de transecto móvel em cinco dias do verão de 2014, no mês de janeiro. Os dados coletados foram devidamente organizados e tratados, procedendo-se posteriormente à elaboração das cartas de isotermas e de isoígras. A análise dos dados e das cartas demonstrou a formação de ilhas de calor da ordem de até $7,6^{\circ} \mathrm{C}$ no período considerado com um maior aquecimento na área central, caracterizada pela localização no vale principal do Rio Paraibuna, pela incipiente cobertura vegetal arbórea, pela grande densidade demográfica e habitacional e pelo intenso e constante fluxo diário de veículos. Os dados coletados permitiram também o cálculo do Índice de Desconforto e da Temperatura Efetiva e a sua classificação com base na distribuição das zonas de conforto para diferentes graus de percepção térmica e as suas respostas fisiológicas. Posteriormente, procedeu-se à correlação das zonas de conforto com os condicionantes geoecológicos e geourbanos. A análise demonstra a produção de zonas de desconforto térmico que podem produzir um nível de estresse fisiológico caracterizado pela ocorrência de vasoconstrição (sensação térmica "ligeiramente fresco") ou vasodilatação (sensação térmica "ligeiramente quente").
\end{abstract}

Palavras-chave: clima urbano; ilhas de calor urbanas; conforto térmico humano.

\section{ABSTRACT}

The research was based on the theoretical-methodological proposal of Monteiro (1976) for the study of the Urban Climate System in Juiz de Fora, a city that has experienced an intense process of demographic growth and urban expansion in recent decades. The focus of the research is the thermodynamic subsystem, whose channel of perception includes the research on the urban heat islands. The data collection of temperature and relative humidity was performed through a mobile transect in five days of the 2014 summer, in January. The data collected were duly organized and treated, and the isotherms and isographs were subsequently elaborated. The data and charts analysis showed the formation of heat islands of up to $7,6^{\circ} \mathrm{C}$ in the considered period, with a greater heating in the central area, characterized by the location in the main valley of the Paraibuna River, by the incipient arboreal vegetation cover, the demographic and housing density and the intense and constant daily flow of vehicles. The data collected also allowed the calculation of the Discomfort Index and Effective Temperature and its classification based on the distribution of comfort zones for different degrees of thermal perception and their physiological responses. Subsequently, the zones of comfort were correlated with the geoecological and geourbans conditioners. The analysis demonstrates the production of thermal discomfort zones that can produce a level of physiological stress characterized by the occurrence of vasoconstriction ("slightly cool" thermal sensation) or vasodilatation ("slightly hot" thermal sensation).

Key-words: urban climate; urban heat islands; human thermal comfort.

Recebido em: 16/03/2017

Aceito em: 28/05/2018

\footnotetext{
1 Instituto Doctum de Educação e Tecnologia, Juiz de Fora/MG, e-mail: christianric@hotmail.com

2 Instituto Doctum de Educação e Tecnologia, Juiz de Fora/MG, e-mail: ambiental_work@hotmail.com

3 Instituto Doctum de Educação e Tecnologia, Juiz de Fora/MG, e-mail: fabriciopbastos@gmail.com
} 
Ribeiro, C. R.; Gonçalves, A. P.; Bastos, F. P.

\section{ILHAS DE CALOR URBANAS E CONFORTO TÉRMICO HUMANO EM CIDADES DE PORTE MÉDIO: ESTUDO APLICADO EM JUIZ DE FORA (MG)}

\section{INTRODUÇÃO}

O processo de urbanização intensificou-se e acelerou-se em todo o mundo nas últimas décadas, especialmente nos países subdesenvolvidos. As áreas urbanas são, atualmente, o local de residência de metade da população do planeta. A cidade, ao se tornar a maior expressão das modificações realizadas pelo ser humano, reflete a conturbada relação entre o homem e a natureza.

No Brasil esse processo não foi diferente, especialmente com a intensificação da urbanização ocorrida no pós-Segunda Guerra Mundial. A maioria das cidades brasileiras cresceu sem um planejamento urbano adequado, tendo como consequência o surgimento e mesmo o agravamento de diversos problemas de ordem ambiental e social. Nesse contexto, o aquecimento da atmosfera próxima à superfície urbanizada é um fato conhecido, com efeitos preocupantes sobre a cidade, pois acarreta a formação de ilhas de calor, a inversão térmica, a poluição do ar, a mudança na direção e na velocidade dos ventos, a diminuição da umidade relativa do ar e a intensificação das precipitações, propiciando a produção de um clima diferenciado para a cidade, qual seja o clima urbano (ORTIZ, 2012, p. 16).

O clima urbano, de acordo com o arcabouço teórico-metodológico proposto por Monteiro (1976), constitui uma organização complexa que admite uma visão sistêmica, com vários graus de hierarquia funcional e diferentes níveis hierárquicos. O clima da cidade, ou Sistema Clima Urbano (S.C.U.), deve ser compreendido como um sistema cuja produção e funcionamento seriam o resultado da interação dinâmica entre os subsistemas Termodinâmico, Físico-Químico e Hidrodinâmico que, por sua vez, expressam-se através de canais de percepção que se iniciam na essência da atmosfera e desembocam na percepção humana: conforto térmico, qualidade do ar e impacto meteórico, respectivamente (MONTEIRO, 2011).

Uma das características mais notáveis do clima urbano, portanto, é o aumento da temperatura do ar, com a consequente formação de ilhas de calor. As características cada vez mais marcantes das cidades, como a elevada densidade demográfica, a concentração de áreas construídas, a pavimentação asfáltica e as áreas industriais, podem provocar alterações no clima local, especialmente nos valores de temperatura do ar (LOMBARDO, 1985, p. 27).

Considerando que o conforto fisiológico do homem é determinado principalmente pela temperatura, pelo vento e pela umidade (AYOADE, 2002, p. 289-290) e que as modificações provocadas pela urbanização no comportamento destes elementos climáticos podem resultar em desconforto térmico, redução do desempenho humano e mesmo em problemas sanitários (MONTEIRO, 2011, p. 46), o estudo do Subsistema Termodinâmico através de seu canal de percepção adquire relevância no sentido de orientar as ações de planejamento urbano.

Apesar de os grandes centros urbanos serem as áreas que mais sofrem os efeitos negativos das alterações produzidas pela urbanização sobre o clima das cidades e, consequentemente, sobre a qualidade de vida de suas populações, as cidades de pequeno e de médio porte têm merecido cada vez mais atenção dos estudiosos destas questões. Vários autores, tais como Mendonça (1994), Ortiz (2012) e Viana e Amorim (2009), apontaram em seus estudos os efeitos negativos da urbanização nessas cidades. Mendonça (2011, p. 182) destaca que as cidades de médio e pequeno porte têm sido objeto de estudo constante dos pesquisadores do clima urbano no Brasil nos últimos anos, sendo a investigação do campo termodinâmico o enfoque predominante de pesquisa, devido à sua condição de tropicalidade, que em muitos casos contribui para o agravamento do desconforto térmico.

Neste contexto inclui-se Juiz de Fora, uma cidade de porte médio localizada na Zona da Mata de Minas Gerais, que passou por um intenso e acelerado processo de crescimento demográfico e de expansão urbana nas últimas 
Ribeiro, C. R.; Gonçalves, A. P.; Bastos, F. P.

\section{ILHAS DE CALOR URBANAS E CONFORTO TÉRMICO HUMANO EM CIDADES DE PORTE MÉDIO: ESTUDO APLICADO EM JUIZ DE FORA (MG)}

décadas, resultando em um conjunto de benefícios e de problemas. Segundo os dados dos Censos Demográficos do IBGE, a população municipal, que era de 238.510 habitantes em 1970, atingiu o total de 516.247 habitantes em 2010. A taxa de urbanização, que era de $92,40 \%$ em 1970, chegou a 98,86\% em 2010.

Levando-se em conta que a maioria dos estudos acerca do clima urbano está voltada para cidades de grande porte, a presente pesquisa adquire relevância ao propor a análise do subsistema termodinâmico do Sistema Clima Urbano numa cidade de porte médio, em um contexto em que essa categoria de cidades vem assumindo uma importância cada vez maior na rede urbana brasileira. Nesse sentido, é fundamental o desenvolvimento de pesquisas que contribuam para o debate a respeito do equilíbrio da expansão territorial em cidades de porte médio, produzindo dados e informações que subsidiem alternativas mais adequadas de planejamento ambiental urbano por parte do Poder Público no âmbito municipal.

\section{MATERIAIS E MÉTODOS}

O presente estudo adota como referencial teórico-metodológico básico as proposições elaboradas por Monteiro (1976) a respeito do Sistema Clima Urbano (S.C.U.). Mais especificamente, o foco da pesquisa está no Subsistema Termodinâmico do S.C.U., que apresenta o Conforto Térmico como o seu canal de percepção. Inicialmente, foi realizada uma ampla revisão bibliográfica, incluindo os conceitos, métodos e técnicas correlatos ao desenvolvimento da pesquisa. A revisão incluiu temas como estudos de clima urbano no Brasil e no mundo, clima das cidades e ilhas de calor urbanas.

Posteriormente, realizou-se a caracterização do uso e cobertura da terra no Município de Juiz de Fora, com o objetivo de subsidiar a seleção de áreas representativas da cidade para a coleta de dados de temperatura atmosférica e de umidade relativa do ar. Para tanto, foi elaborado um mapa a partir das imagens do satélite Landsat 8 , disponibilizadas gratuitamente no sítio eletrônico da United States Geological Survey (USGS). Foi utilizada uma cena datada de 21/04/2013, com resolução espacial de 30 metros. Optou-se por uma composição RGB falsa cor $(6,5,4)$ com três das bandas multiespectrais. Posteriormente, procedeu-se à fusão da imagem composta com a banda pancromática (banda 8), com resolução espacial de 15 metros, obtendo-se um produto final com esta mesma resolução, constituindose na fonte de dados básica para a elaboração do mapa. A definição das classes foi realizada a partir da elaboração de uma chave de interpretação, de acordo com os procedimentos descritos por IBGE (2006) e por Novo (1995). Além disso, foram realizados trabalhos de campo para a verificação e a validação do trabalho de caracterização realizado em escritório. O mapa (Figura 1) foi produzido com - auxílio do aplicativo $\operatorname{ArcGIS}^{\circledR}$ (ArcMapTM Version 10.1), através do qual procedeu-se à vetorização das classes de uso e cobertura da terra sobre a imagem de satélite.

O transecto sudeste-noroeste parte do bairro Vila Ideal e estende-se até o bairro Barreiro do Triunfo, contabilizando um total de 220 pontos de coleta, ao passo que o transecto sudoeste-nordeste parte do bairro São Pedro e estende-se até o bairro Grama, contabilizando um total de 210 pontos de coleta. A observação e a análise dos dados coletados nos cinco dias, bem como das cartas de isotermas e de isoígras e do mapa de uso e cobertura da terra, permite o fracionamento dos transectos em trechos individualizados, que caracterizam-se por apresentar certa particularidade dos condicionantes geoecológicos e geourbanos, o que leva, por conseguinte, à identificação de um padrão de variação espacial da temperatura e da umidade relativa intraurbanas em Juiz de Fora. O Quadro 1 apresenta a caracterização desses trechos.

A coleta dos dados climatológicos que subsidiaram a pesquisa foi realizada com o auxílio da técnica do transecto móvel noturno (medidas itinerantes). O transecto móvel noturno consistiu na tomada de dados de 
Ribeiro, C. R.; Gonçalves, A. P.; Bastos, F. P.

\section{ILHAS DE CALOR URBANAS E CONFORTO TÉRMICO HUMANO EM CIDADES DE PORTE MÉDIO: ESTUDO APLICADO EM JUIZ DE FORA (MG)}

temperatura e de umidade relativa do ar na área intraurbana de Juiz de Fora, com início no horário de 20h30min, horário no qual verifica-se uma maior estabilidade das condições atmosféricas e baixa variação natural da temperatura do ar entre o início e o final do transecto. A coleta foi realizada durante cinco dias não consecutivos do verão de 2014 (13, 14,
15, 20 e 21/01/2014) e em condições de estabilidade atmosférica (céu limpo e claro, sem ventos de forte intensidade e sem precipitação); contemplou todas as diferentes unidades de uso e cobertura da terra identificadas e teve tempo máximo de 50 minutos para percorrer os trajetos previamente definidos.

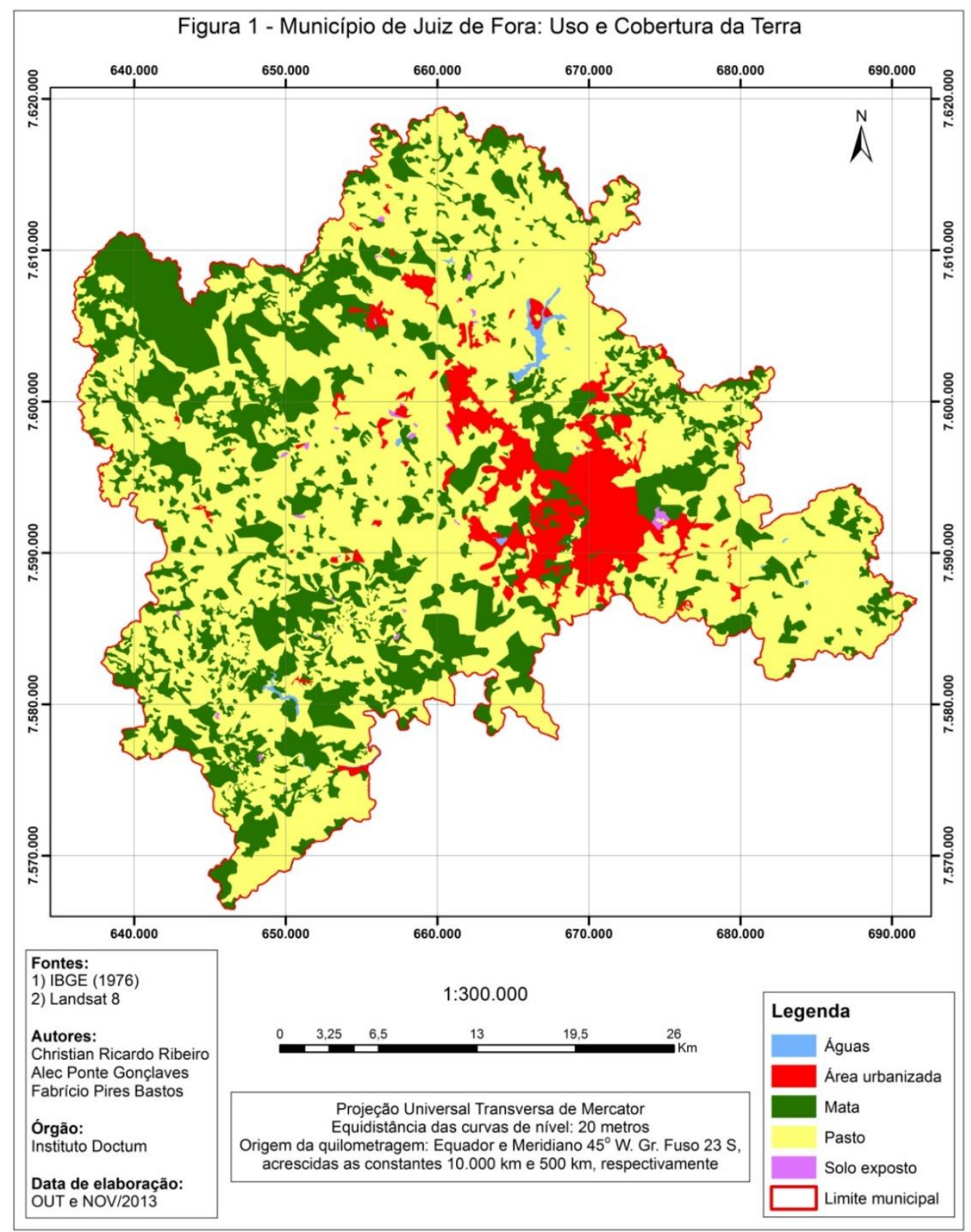

Figura 1 - Município de Juiz de Fora: Uso e Cobertura da Terra.

\begin{tabular}{|c|c|c|c|}
\hline \multicolumn{3}{|c|}{ Quadro 1-Condicionantes geoecológicos e geourbanos dos transectos móveis } \\
\hline Transectos & Localização & $\begin{array}{c}\text { Condicionantes } \\
\text { geoecológicos }\end{array}$ & $\begin{array}{c}\text { Condicionantes } \\
\text { geourbanos }\end{array}$ \\
\hline
\end{tabular}


Ribeiro, C. R.; Gonçalves, A. P.; Bastos, F. P.

ILHAS DE CALOR URBANAS E CONFORTO TÉRMICO HUMANO EM CIDADES DE PORTE MÉDIO: ESTUDO APLICADO EM JUIZ DE FORA (MG)

\begin{tabular}{|c|c|c|c|c|}
\hline Cara & terísticas & & & \\
\hline \multirow{3}{*}{$\begin{array}{l}\text { SE-NW } \\
\text { (Vila } \\
\text { Ideal - } \\
\text { Barreira } \\
\text { do } \\
\text { Triunfo) }\end{array}$} & $\begin{array}{l}\text { Trecho } 1 \\
\text { (Pontos } \\
1 \text { a 20) }\end{array}$ & $\begin{array}{l}\text { Extremo da malha } \\
\text { urbana (sudeste); } \\
\text { compacta, é contígua } \\
\text { ao centro e estende-se } \\
\text { até a transição para a } \\
\text { área rural. }\end{array}$ & $\begin{array}{l}\text { Morfologia de fundo de vale (Rio } \\
\text { Paraibuna). Cobertura vegetal } \\
\text { arbórea baixa a média. }\end{array}$ & $\begin{array}{l}\text { Verticalização baixa. } \\
\text { Densidade demográfica e } \\
\text { habitacional média. } \\
\text { Circulação de veículos } \\
\text { baixa a média. }\end{array}$ \\
\hline & $\begin{array}{l}\text { Trecho } 2 \\
\text { (Pontos } \\
21 \text { a } 80 \text { ) }\end{array}$ & Área central da cidade. & $\begin{array}{l}\text { Morfologia de fundo de vale (Rio } \\
\text { Paraibuna). Cobertura vegetal } \\
\text { arbórea baixa. }\end{array}$ & $\begin{array}{l}\text { Verticalização alta. } \\
\text { Densidade demográfica e } \\
\text { habitacional alta. } \\
\text { Circulação de veículos alta } \\
\text { e constante durante todo o } \\
\text { dia. }\end{array}$ \\
\hline & $\begin{array}{l}\text { Trecho } 3 \\
\text { (Pontos } \\
81 \text { a } \\
220 \text { ) }\end{array}$ & $\begin{array}{l}\text { Vetor noroeste da } \\
\text { malharana; } \\
\text { bastante alongada, } \\
\text { estende-se do centro à } \\
\text { transição para a área } \\
\text { rural. }\end{array}$ & $\begin{array}{l}\text { Morfologia de fundo de vale } \\
\text { predominante (Rio Paraibuna) e } \\
\text { pequeno trecho em topos e } \\
\text { vertentes. Cobertura vegetal } \\
\text { arbórea baixa a média, com } \\
\text { cobertura alta nas proximidades } \\
\text { da Mata do Krambeck. }\end{array}$ & $\begin{array}{l}\text { Verticalização baixa. } \\
\text { Densidade demográfica e } \\
\text { habitacional baixa a média. } \\
\text { Circulação de veículos } \\
\text { baixa a média. }\end{array}$ \\
\hline \multirow{3}{*}{$\begin{array}{l}\text { SW-NE } \\
\text { (São } \\
\text { Pedro - } \\
\text { Grama) }\end{array}$} & $\begin{array}{l}\text { Trecho } 1 \\
\text { (Pontos } \\
1 \text { a } 80 \text { ) }\end{array}$ & $\begin{array}{lll}\text { Cidade } & \text { Alta } & \text { (vetor } \\
\text { oeste } & \text { da } & \text { malha } \\
\text { urbana). } & & \end{array}$ & $\begin{array}{l}\text { Morfologia de topos e vertentes, } \\
\text { declividades elevadas e cotas } \\
\text { altimétricas }(900 \mathrm{~m}) \text { bastante } \\
\text { superiores em relação ao centro } \\
\text { da cidade }(670 \mathrm{~m}) \text {. Cobertura } \\
\text { vegetal arbórea média a alta, } \\
\text { com presença significativa de } \\
\text { remanescentes de Mata } \\
\text { Atlântica. }\end{array}$ & $\begin{array}{l}\text { Verticalização baixa. } \\
\text { Densidade demográfica e } \\
\text { habitacional baixa nas } \\
\text { áreas de condomínios } \\
\text { exclusivos e áreas } \\
\text { periféricas e baixa a média } \\
\text { nas áreas de ocupação } \\
\text { antiga e consolidada do } \\
\text { bairro São Pedro e } \\
\text { arredores. Circulação de } \\
\text { veículos baixa a média. }\end{array}$ \\
\hline & $\begin{array}{l}\text { Trecho } 2 \\
\text { (Pontos } \\
81 \text { a } \\
155)\end{array}$ & Área central da cidade. & $\begin{array}{l}\text { Morfologia de fundo de vale (Rio } \\
\text { Paraibuna). Cobertura vegetal } \\
\text { arbórea alta. }\end{array}$ & $\begin{array}{l}\text { Verticalização alta. } \\
\text { Densidade demográfica e } \\
\text { habitacional alta. } \\
\text { Circulação de veículos alta } \\
\text { e constante durante todo o } \\
\text { dia. }\end{array}$ \\
\hline & $\begin{array}{l}\text { Trecho } 3 \\
\text { (Pontos } \\
156 \text { a } \\
210 \text { ) }\end{array}$ & $\begin{array}{l}\text { Vetor nordeste da } \\
\text { malha urbana; } \\
\text { bastante alongada, } \\
\text { estende-se do centro à } \\
\text { transição para a área } \\
\text { rural. }\end{array}$ & $\begin{array}{l}\text { Morfologia de topos e vertentes, } \\
\text { declividades elevadas em alguns } \\
\text { trechos e cotas altimétricas } \\
\text { bastante superiores em relação } \\
\text { ao centro da cidade. Cobertura } \\
\text { vegetal arbórea média a alta, } \\
\text { com presença significativa de } \\
\text { remanescentes de Mata } \\
\text { Atlântica. }\end{array}$ & $\begin{array}{l}\text { Verticalização baixa. } \\
\text { Densidade demográfica e } \\
\text { habitacional baixa a média. } \\
\text { Circulação de veículos } \\
\text { baixa a média. }\end{array}$ \\
\hline
\end{tabular}

Foram coletos dados em 220 pontos no transecto sudeste-noroeste e em 210 pontos no transecto sudoeste-nordeste (Figura 2). Assim, dois veículos equipados com termo-higrômetros digitais (tipo "Termomettro Max. e Min. Mod. 9950.02.1.00 VCAH NF. 152706"), com sensores instalados em hastes a 1,5 $\mathrm{m}$ de altura em suas laterais, percorreram sincronicamente os trajetos pré-determinados para proceder à coleta de dados. A velocidade máxima de deslocamento dos veículos esteve sempre entre 30 e $40 \mathrm{~km} / \mathrm{h}$. Os trabalhos de Amorim (2005a e 2005 b), Amorim, Sant'Anna Neto e Dubreuil (2009), Araújo et al. (2010), Ortiz (2012), Santos e Nogueira (2012) e Ugeda Júnior e Amorim (2012) constituíram-se em referências importantes para a organização do trabalho de campo visando à coleta de dados através de transectos móveis.

Os dados coletados foram tabulados e tratados no Excel $^{\circledR}$, gerando planilhas com valores de temperatura atmosférica em graus Celsius e umidade relativa do ar em porcentagem. Posteriormente, as planilhas foram utilizadas na elaboração de gráficos e de cartas de variação da temperatura e da umidade nos dois transectos traçados sobre a malha urbana. As cartas foram elaboradas com o 


\section{ILHAS DE CALOR URBANAS E CONFORTO TÉRMICO HUMANO EM CIDADES DE PORTE MÉDIO: ESTUDO APLICADO EM JUIZ DE FORA (MG)}

auxílio do aplicativo $\operatorname{ArcGIS}^{\circledR}$ (versão 10.1). Finalmente, foi realizada a análise da variação espacial da temperatura e da umidade relativa do ar nos dias analisados e a sua correlação com os condicionantes geoecológicos e geourbanos de Juiz de Fora.

A avaliação do conforto térmico humano utilizou-se dos dados de temperatura e de umidade relativa do ar coletados através do transecto móvel. A literatura apresenta uma grande variedade de metodologias empregadas pela Climatologia Geográfica brasileira na avaliação das condições de conforto térmico. Foram selecionados dois dos índices apresentados por Maia e Gonçalves (2002, p. 306). O primeiro índice (Equação 1) é uma adaptação de Giles, Balafouts e Maheras (1990) do Índice de Desconforto (ID) proposto por Thom (1959) e o segundo índice (Equação 2) é uma adaptação de Ono e Kawamura (1991) do Índice de Temperatura e Umidade (ITU) ou Temperatura Efetiva (TE) proposto por Missenard (1937).

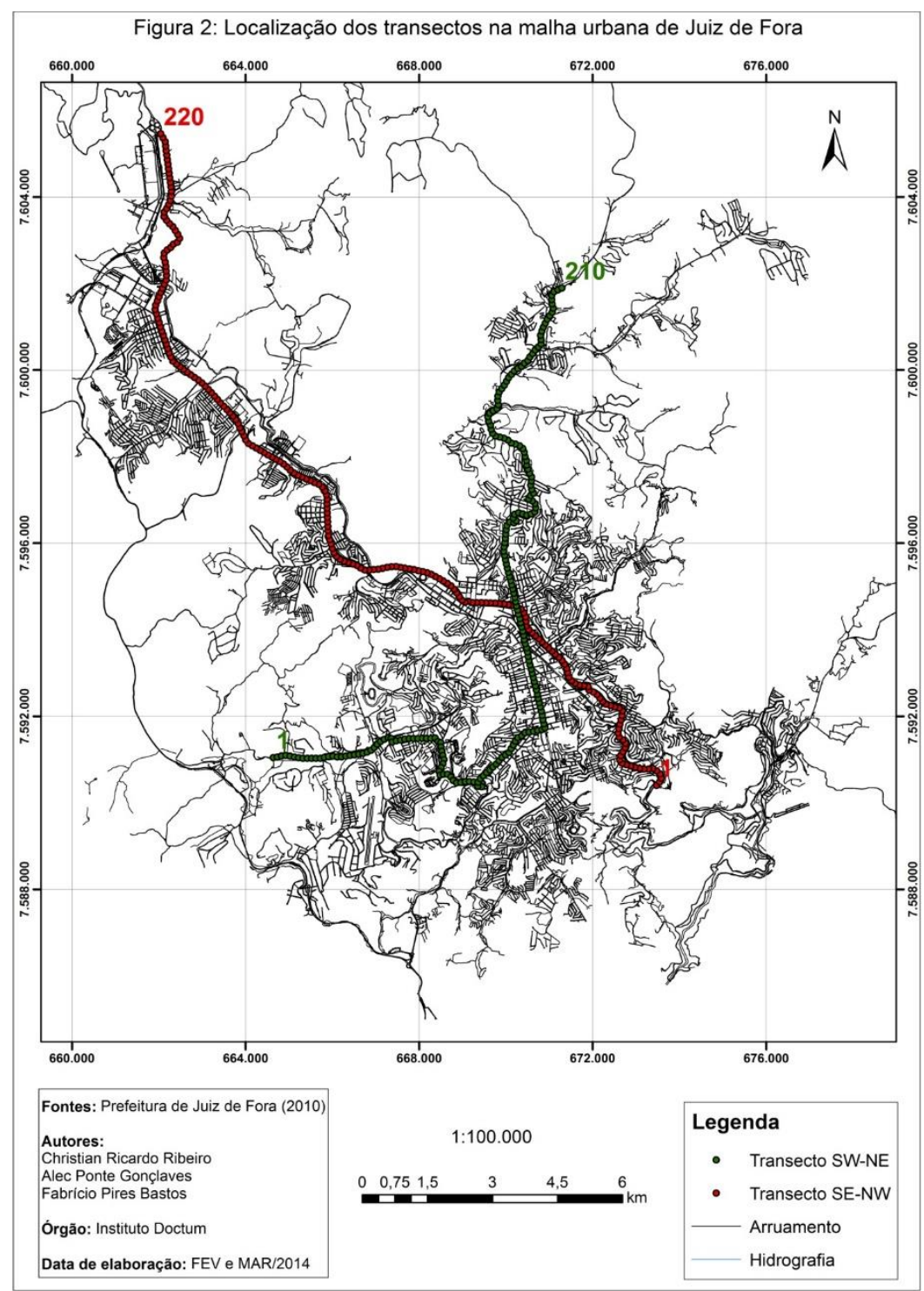

Figura 2 - Localização dos transectos na malha urbana de Juiz de Fora.

Esses índices, além de se basearem em variáveis ambientais de fácil obtenção, são comumente utilizados para a avaliação do conforto térmico em ambientes abertos 
Ribeiro, C. R.; Gonçalves, A. P.; Bastos, F. P.

\section{ILHAS DE CALOR URBANAS E CONFORTO TÉRMICO HUMANO EM CIDADES DE PORTE MÉDIO: ESTUDO APLICADO EM JUIZ DE FORA (MG)}

expostos à radiação, podendo ser adequadamente adaptados e aplicados às regiões tropicais (SOUZA e NERY, 2012, p. 75).

$\mathrm{ID}=\mathrm{Ta}-0,55 *(1-0,01 \mathrm{UR}) *(\mathrm{Ta}-14,5)$ (Equação 1)

$$
\mathrm{TE}=\mathrm{Ta}-0,4 *(\mathrm{Ta}-10) *(1-0,01 \mathrm{UR})
$$

(Equação 2)

Sendo: Ta $=$ temperatura do ar (bulbo seco, em oC) e $\mathrm{UR}=$ umidade relativa do ar (em \%), em ambas as equações.

Os dados de temperatura e de umidade foram tabulados e organizados no Excel $^{\circledR}$.
Posteriormente, com o auxílio das ferramentas de fórmulas do aplicativo, foram calculados o Índice de Desconforto e a Temperatura Efetiva para cada um dos pontos pertencentes aos dois transectos nos cinco dias em que foi realizada a coleta de dados. A avaliação dos níveis de conforto térmico com base nos dois índices calculados foi realizada com base na distribuição das zonas de conforto adotada pelo Laboratório de Meteorologia Aplicada a Sistemas de Tempo Regionais (MASTER - Instituto de Astronomia, Geofísica e Ciências Atmosféricas da Universidade de São Paulo), uma adaptação da proposta de Fanger (1972), conforme mostra a Tabela 1.

\begin{tabular}{c|l|l}
\multicolumn{2}{c}{ Tabela 1 - Distribuição das zonas de conforto para diferentes graus de percepção térmica e } \\
suas respostas fisiológicas
\end{tabular}

Quadro 1 - Distribuição das zonas de conforto para diferentes graus de percepção térmica e suas respostas fisiológicas. Fonte: Laboratório MASTER (IAG/USP). Disponível em: <http://www.master.iag.usp.br>. Acesso em: 15 fev. 2015.

\section{Resultados e Discussão}

A análise conjunta do Boletim Técnico do Centro de Previsão de Tempo e Estudos Climáticos do Instituto Nacional de Pesquisas Espaciais (CPTEC/INPE), das cartas sinóticas de superfície da Marinha do Brasil e das imagens do satélite Goes referentes ao período de coleta de dados permite identificar uma atuação intermitente da Zona de Convergência do Atlântico Sul (ZCAS) no período de realização da coleta através dos transectos. Entre os dias 16/01 e 19/01 verificou-se a atuação da Zona de Convergência de Umidade (ZCOU), o que provocou chuvas e inviabilizou a realização da coleta de dados através do transecto móvel nesse período. Nos cinco dias de realização do transecto, a coleta de dados foi realizada sob condições de estabilidade atmosférica (céu claro, sem precipitação e sem ventos de intensidade significativa). Os dias 14/01/2014 e $15 / 01 / 2014$ foram aqueles nos quais verificouse a ilhas de calor de maior intensidade.

Segundo os dados da Estação Meteorológica Automática (EMA) de Juiz de Fora, as condições atmosféricas nos dias em que foram realizadas as coletas eram:

- 13/01/2014: temperatura máxima de $28,7^{\circ} \mathrm{C}$ (17h UTC), temperatura mínima de $19,6^{\circ} \mathrm{C}$ ( $8 \mathrm{~h}$ UTC), velocidade do vento de $3,7 \mathrm{~m} / \mathrm{s}$, direção do vento de $70^{\circ}$, pressão atmosférica de 912,9 $\mathrm{hPa}$ e precipitação de $0,0 \mathrm{~mm}$. 


\section{ILHAS DE CALOR URBANAS E CONFORTO TÉRMICO HUMANO EM CIDADES DE PORTE MÉDIO: ESTUDO APLICADO EM JUIZ DE FORA (MG)}

- 14/01/2014: temperatura máxima de $29,0^{\circ} \mathrm{C}$ (18h UTC), temperatura mínima de $19,4^{\circ} \mathrm{C}(8 \mathrm{~h}$ UTC), velocidade do vento de $2,9 \mathrm{~m} / \mathrm{s}$, direção do vento de $59^{\circ}$, pressão atmosférica de 910,8 hPa e precipitação de 0,0 mm.

- 15/01/2014: temperatura máxima de $30,5^{\circ} \mathrm{C}$ (18h UTC), temperatura mínima de $20,2^{\circ} \mathrm{C}$ ( $8 \mathrm{~h}$ UTC), velocidade do vento de $1,9 \mathrm{~m} / \mathrm{s}$, direção do vento de $36^{\circ}$, pressão atmosférica de 909,3 hPa e precipitação de 0,0 mm.

- 20/01/2014: temperatura máxima de $27,0^{\circ} \mathrm{C}$ (18h UTC), temperatura mínima de $18,0^{\circ} \mathrm{C}(8 \mathrm{~h}$ UTC), velocidade do vento de $3,5 \mathrm{~m} / \mathrm{s}$, direção do vento de $106^{\circ}$, pressão atmosférica de 909,7 hPa e precipitação de $0,0 \mathrm{~mm}$.

- 21/01/2014: temperatura máxima de $28,1^{\circ} \mathrm{C}$ (16h UTC), temperatura mínima de $18,4^{\circ} \mathrm{C}$ ( $8 \mathrm{~h}$ UTC), velocidade do vento de $1,3 \mathrm{~m} / \mathrm{s}$, direção do vento de $11^{\circ}$, pressão atmosférica de 909,8 hPa e precipitação de $0,0 \mathrm{~mm}$.

A análise do Quadro 1 e dos dados coletados permite observar que, a partir da conjugação dos fatores geoecológicos e geourbanos, pode ser identificada uma tendência geral de variação espacial da temperatura do ar e, consequentemente, da umidade relativa ao longo dos dois transectos. Nos dois transectos, a área central (trecho 2) é a que apresenta o maior potencial de aquecimento, em função da maior intensidade dos fatores geourbanos. Os extremos dos transectos (trechos 1 e 3 dos dois transectos) tendem a apresentar as menores temperaturas, que vão aumentando ou diminuindo progressivamente na medida em que se aproxime ou se afaste do centro, respectivamente. Os fatores geoecológicos aparecem aí com uma grande influência.

Em alguns trechos essa tendência geral é levemente alterada em função da intensificação da densidade demográfica e habitacional, como no trecho compreendido entre os pontos de coleta 100 e 120 do transecto SE-NW, por exemplo. É importante citar a influência exercida pela Mata do Krambeck, atuando diretamente na diminuição da temperatura e no aumento da umidade relativa no trecho compreendido entre os pontos de coleta 80 e 100, apesar de sua proximidade em relação ao centro da cidade.

Levando-se em consideração a relativa homogeneidade das condições de morfologia do terreno e de cobertura vegetam em todo o trecho compreendido pelo transecto sudestenoroeste, é possível afirmar que os fatores que parecem ser determinantes na variação espacial da temperatura e da umidade relativa intraurbanas nessa área são os fatores geourbanos, ou seja, as diferenças de verticalização, de densidade demográfica e habitacional e de intensidade da circulação de veículos.

No transecto sudoeste-nordeste os fatores geoecológicos exercem uma influência tão importante quanto os fatores geourbanos na variação espacial intraurbana da temperatura e da umidade relativa. Registramse, na área compreendida pelo transecto, importantes variações no que tange à morfologia do terreno, ao uso e cobertura da terra e à intensidade da ocupação, com repercussões importantes sobre o comportamento destes dois elementos climáticos.

No trecho 1, por exemplo, localizado numa região de Juiz de Fora tradicionalmente conhecida como "Cidade Alta", registra-se a presença significativa de remanescentes da Mata Atlântica, transformados em amenidades urbanas pelo mercado imobiliário que transformou essa região da cidade em área preferencial para a implantação de condomínios exclusivos destinados à classe média alta desde o início da década de 1990. A circulação de veículos é relativamente menor em relação ao centro, ainda que nos últimos anos venha aumentando significativamente em função de a região ter se tornado a principal área de expansão urbana da cidade, com a implantação de novas áreas residenciais e de um grande número de equipamentos urbanos de uso coletivo, públicos e privados, como instituições de ensino e hospitais, que caracterizam-se por serem atividades geradoras de tráfego. A Tabela 
Ribeiro, C. R.; Gonçalves, A. P.; Bastos, F. P.

\section{ILHAS DE CALOR URBANAS E CONFORTO TÉRMICO HUMANO EM CIDADES DE PORTE MÉDIO: ESTUDO APLICADO EM JUIZ DE FORA (MG)}

2 apresenta a síntese dos resultados das coletas nos dois transectos.

\begin{tabular}{|c|c|c|c|c|c|c|c|c|c|}
\hline \multicolumn{10}{|c|}{ Tabela 2 - Síntese dos dados coletados nos transectos } \\
\hline \multirow{2}{*}{ Transecto } & \multirow{2}{*}{ Dia } & \multicolumn{2}{|c|}{ Tmáx. } & \multicolumn{2}{|c|}{$T_{\text {min. }}$} & \multirow{2}{*}{$\begin{array}{c}\text { Ampl. } \\
\text { térmica } \\
\left({ }^{\circ} \mathrm{C}\right)\end{array}$} & \multirow{2}{*}{$\begin{array}{c}\text { URmáx. } \\
\text { (\%) }\end{array}$} & \multirow{2}{*}{$\begin{array}{c}\text { URmin. } \\
(\%)\end{array}$} & \multirow{2}{*}{$\begin{array}{l}\text { Ampl. } \\
\text { higrom } \\
(\%)\end{array}$} \\
\hline & & $\left({ }^{\circ} \mathrm{C}\right)$ & Trecho & $\left({ }^{\circ} \mathrm{C}\right)$ & Trecho & & & & \\
\hline \multirow{5}{*}{ SE-NW } & $13 / 01$ & 30,3 & 2 & 25,5 & 3 & 4,8 & 79 & 58 & 21 \\
\hline & $14 / 01$ & 29,0 & 2 & 23,8 & 3 & 5,2 & 79 & 58 & 21 \\
\hline & $15 / 01$ & 29,6 & 2 & 24,4 & 3 & 5,2 & 72 & 46 & 26 \\
\hline & $20 / 01$ & 26,6 & 2 & 23,4 & 3 & 3,2 & 83 & 67 & 16 \\
\hline & $21 / 01$ & 28,3 & 2 & 22,8 & 3 & 5,5 & 93 & 64 & 29 \\
\hline \multirow{5}{*}{ SW-NE } & $13 / 01$ & 28,6 & 2 & 21,6 & 1 & 7,0 & 82 & 59 & 23 \\
\hline & $14 / 01$ & 29,1 & 2 & 21,5 & 3 & 7,6 & 85 & 54 & 31 \\
\hline & $15 / 01$ & 29,2 & 2 & 21,6 & 3 & 7,6 & 77 & 43 & 34 \\
\hline & $20 / 01$ & 26,3 & 2 & 21,0 & 3 & 5,3 & 96 & 64 & 32 \\
\hline & $21 / 01$ & 28,0 & 2 & 22,0 & 3 & 6,0 & 90 & 59 & 31 \\
\hline
\end{tabular}

Fonte: trabalho de campo (13, 14, 15, 20 e 21/01/2014).

A análise da variação da temperatura e da umidade ao longo dos transectos (Tabela 2, Figuras 3 a 7 e Gráficos 1 e 2) permite algumas conclusões importantes. No caso do transecto sudeste-noroeste, as temperaturas máximas do transecto são registradas sempre no trecho 2, que corresponde ao centro da cidade, onde a atuação conjunta de condicionantes geoecológicos e geourbanos explica o maior aquecimento. Nos cinco dias em que foi realizado o transecto, a temperatura máxima foi registrada em pontos muito próximos e, em alguns casos, os pontos se repetiram. As temperaturas mínimas do transecto foram sempre registradas no trecho 3. Em todos os dias, à exceção de 15/01/2014, essas temperaturas foram registradas na parte final do transecto, o que corrobora a tendência geral de diminuição da temperatura anteriormente apontada. A variação da umidade relativa do ar apresenta-se inversamente proporcional à variação da temperatura, o que demonstra o alto grau de correlação entre esses dois elementos climáticos, tal como descrito na literatura. No dia 21/01/2014 foi registrada a mais pronunciada ilha de calor, da ordem de $5,50 \mathrm{C}$, podendo ser classificada como de forte intensidade, segundo García (1996).

No caso do transecto sudoestenordeste, as temperaturas máximas do transecto também são registradas sempre no trecho 2, que corresponde ao centro da cidade. O centro representa a área onde os dois transectos interceptam-se, demonstrando o seu maior potencial de aquecimento em relação ao restante da cidade. Nesse caso, nos cinco dias em que foi realizado o transecto, a temperatura máxima também foi registrada em pontos muito próximos e, em alguns casos, os pontos se repetiram ao longo dos dias como os de maior temperatura.

As temperaturas mínimas do transecto foram sempre registradas no trecho 3 , à exceção do dia 15/01/2014. Porém, deve-se ressaltar que mesmo nesse dia a maior parte das temperaturas mais baixas foram registradas em pontos do trecho 3, confirmando a tendência geral de diminuição da temperatura aí verificada. Essas temperaturas também aparecem associadas à parte final do transecto, confirmando o menor aquecimento dessa área em relação às demais áreas da cidade. Destacase aí a influência exercida pela altitude. Nos dias 14 e 15/01/2014 foi registrada a mais pronunciada ilha de calor, da ordem de $7,6^{\circ} \mathrm{C}$, podendo ser classificada como de muito forte intensidade, segundo García (1996). Esta foi a mais pronunciada ilha de calor registrada no estudo como um todo. 
Ribeiro, C. R.; Gonçalves, A. P.; Bastos, F. P.

ILHAS DE CALOR URBANAS E CONFORTO TÉRMICO HUMANO EM CIDADES DE PORTE MÉDIO: ESTUDO APLICADO EM JUIZ DE FORA (MG)

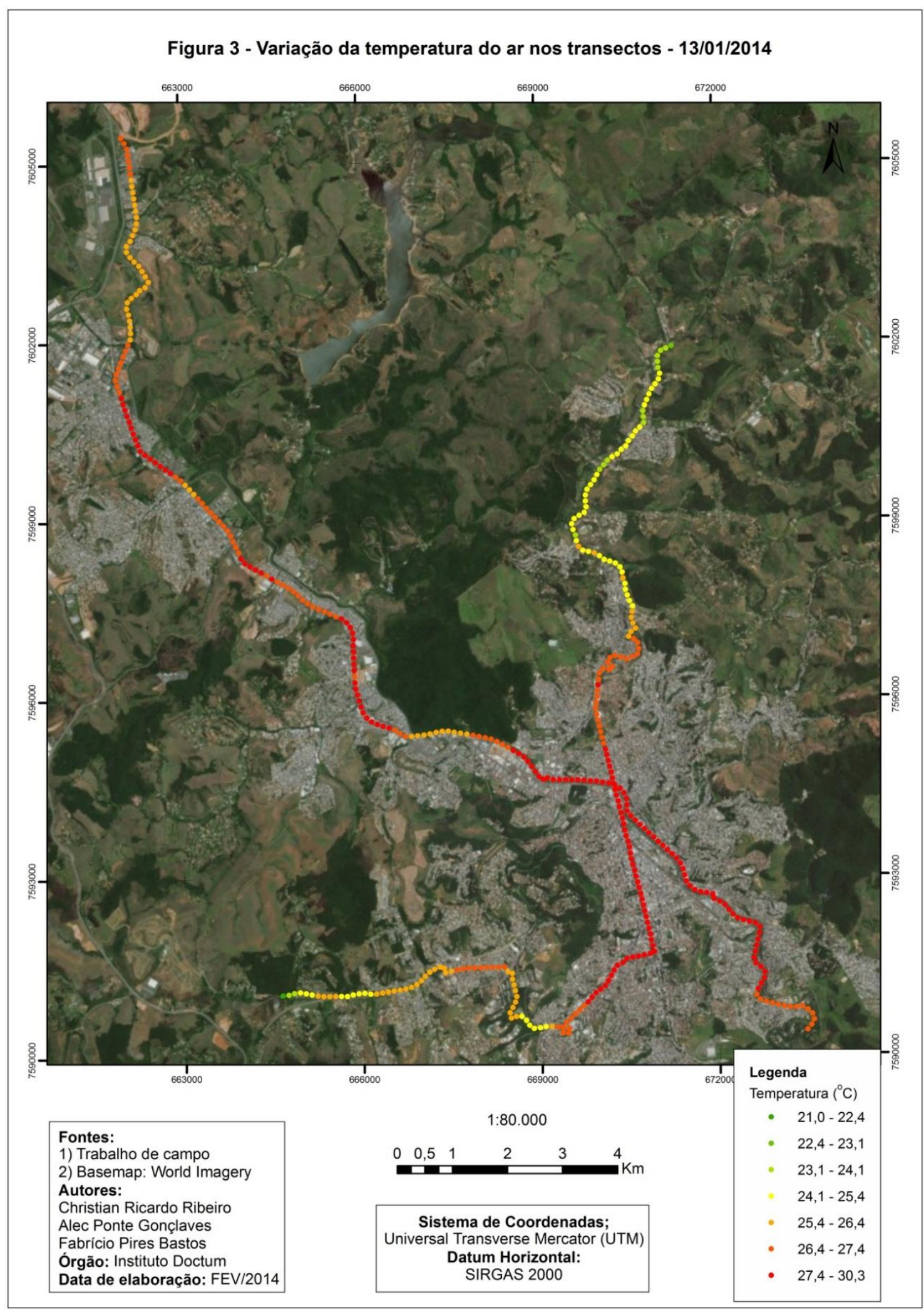

Figura 3 - Variação da temperatura do ar nos transectos - 13/01/2014. 
Ribeiro, C. R.; Gonçalves, A. P.; Bastos, F. P.

ILHAS DE CALOR URBANAS E CONFORTO TÉRMICO HUMANO EM CIDADES DE PORTE MÉDIO: ESTUDO APLICADO EM JUIZ DE FORA (MG)

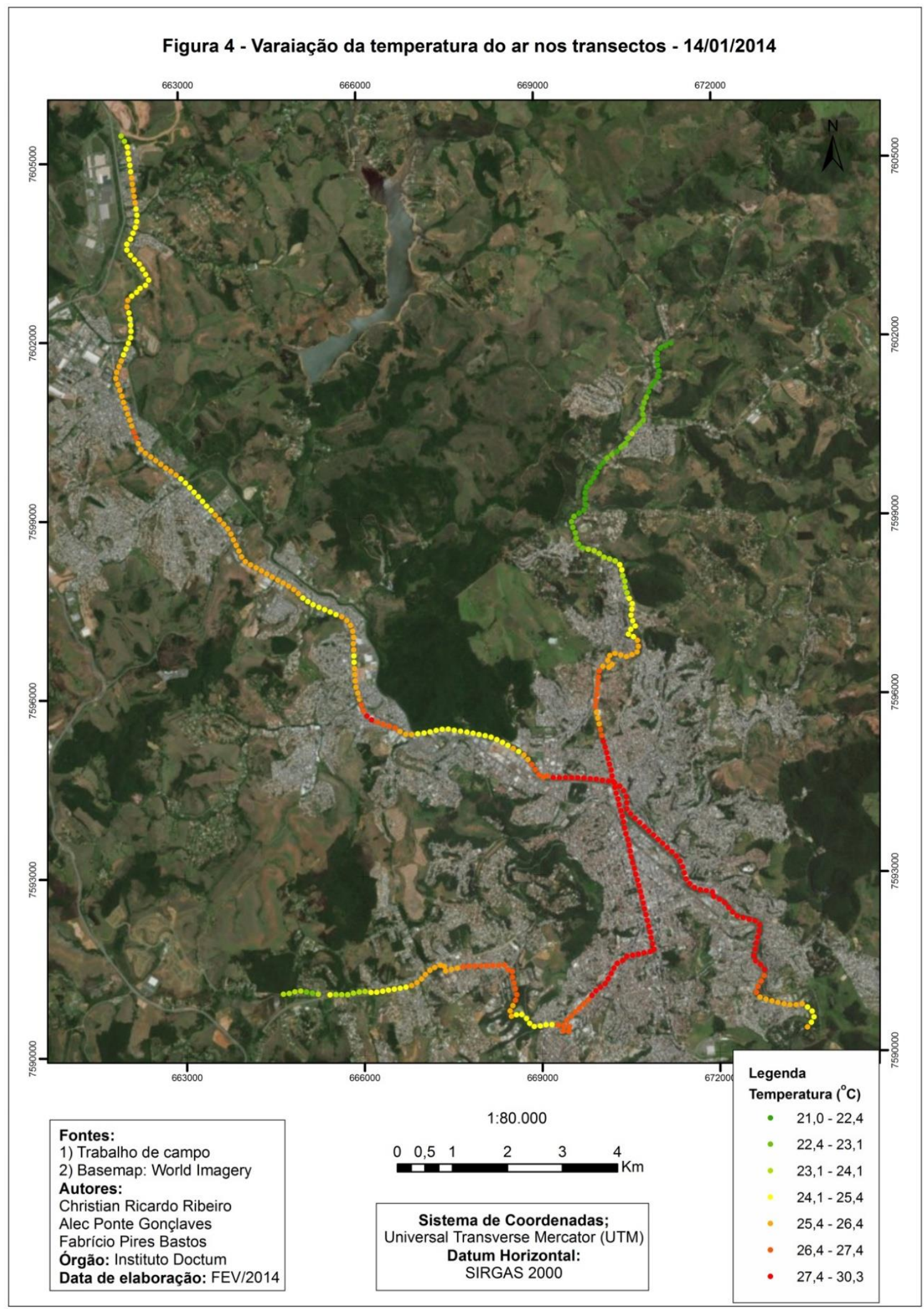

Figura 4 - Variação da temperatura do ar nos transectos - 14/01/2014. 
Ribeiro, C. R.; Gonçalves, A. P.; Bastos, F. P.

ILHAS DE CALOR URBANAS E CONFORTO TÉRMICO HUMANO EM CIDADES DE PORTE MÉDIO: ESTUDO APLICADO EM JUIZ DE FORA (MG)

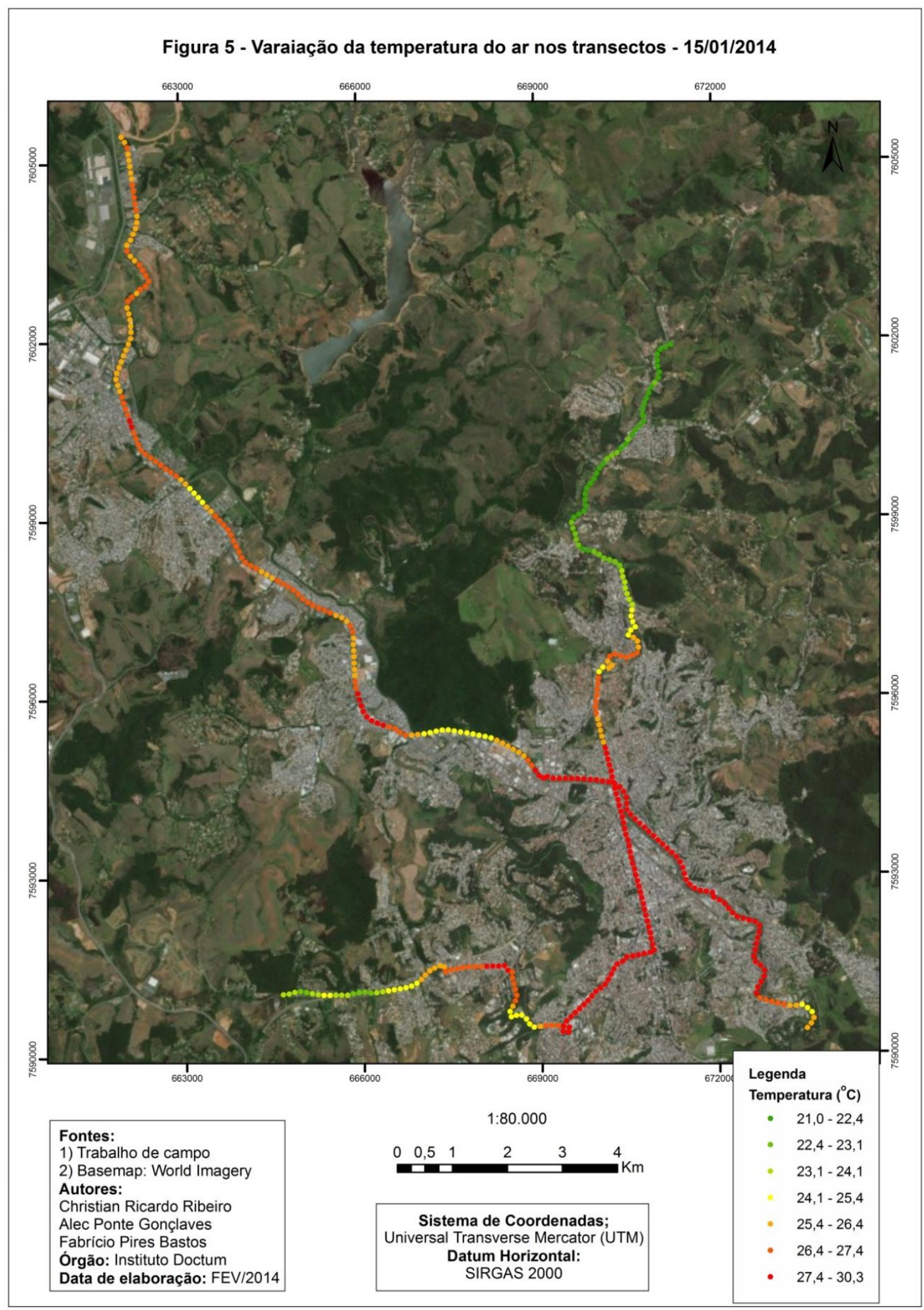

Figura 5 - Variação da temperatura do ar nos transectos - 15/01/2014. 
Ribeiro, C. R.; Gonçalves, A. P.; Bastos, F. P.

ILHAS DE CALOR URBANAS E CONFORTO TÉRMICO HUMANO EM CIDADES DE PORTE MÉDIO: ESTUDO APLICADO EM JUIZ DE FORA (MG)

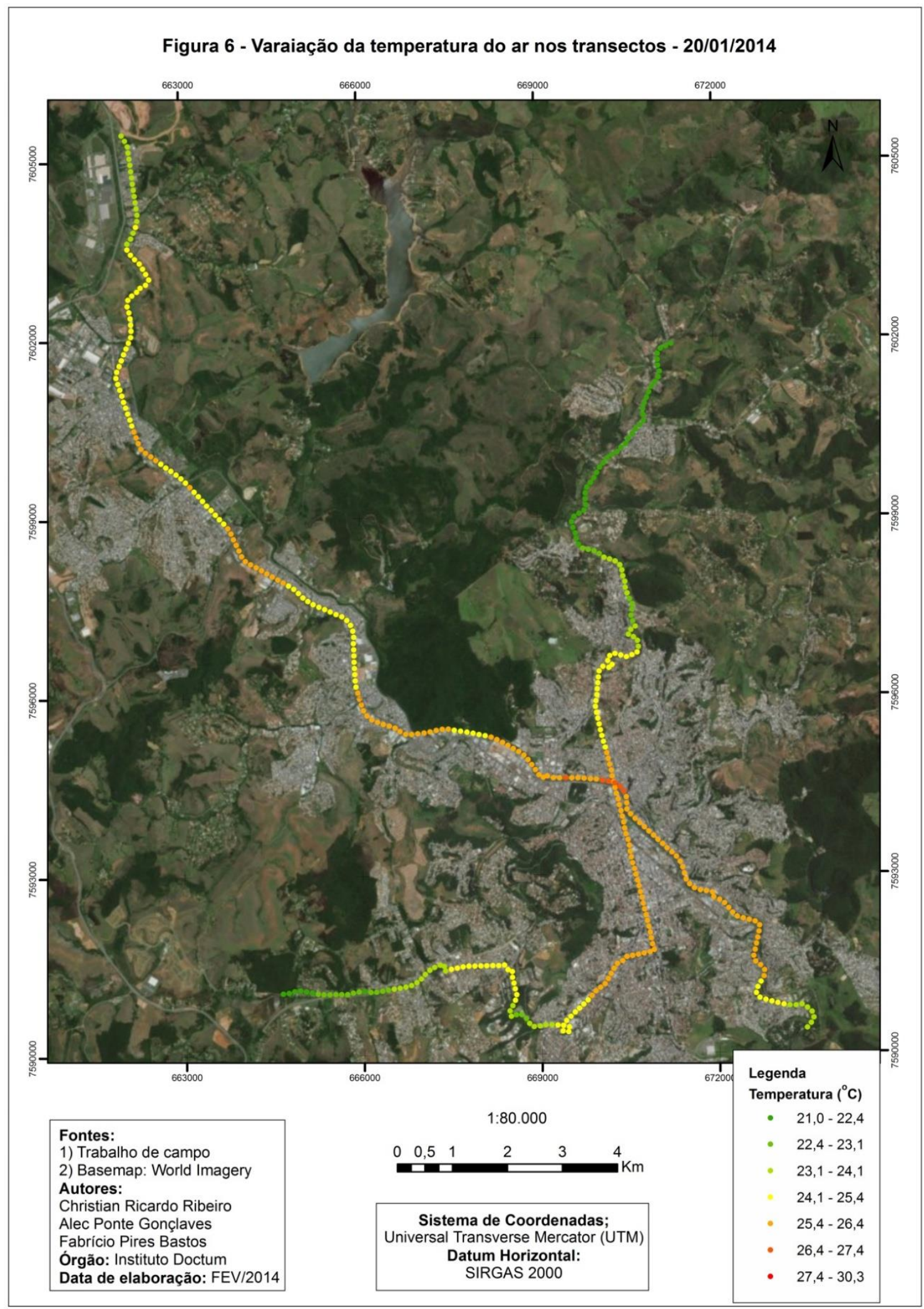

Figura 6 - Variação da temperatura do ar nos transectos - 20/01/2014. 
Ribeiro, C. R.; Gonçalves, A. P.; Bastos, F. P.

ILHAS DE CALOR URBANAS E CONFORTO TÉRMICO HUMANO EM CIDADES DE PORTE MÉDIO: ESTUDO APLICADO EM JUIZ DE FORA (MG)

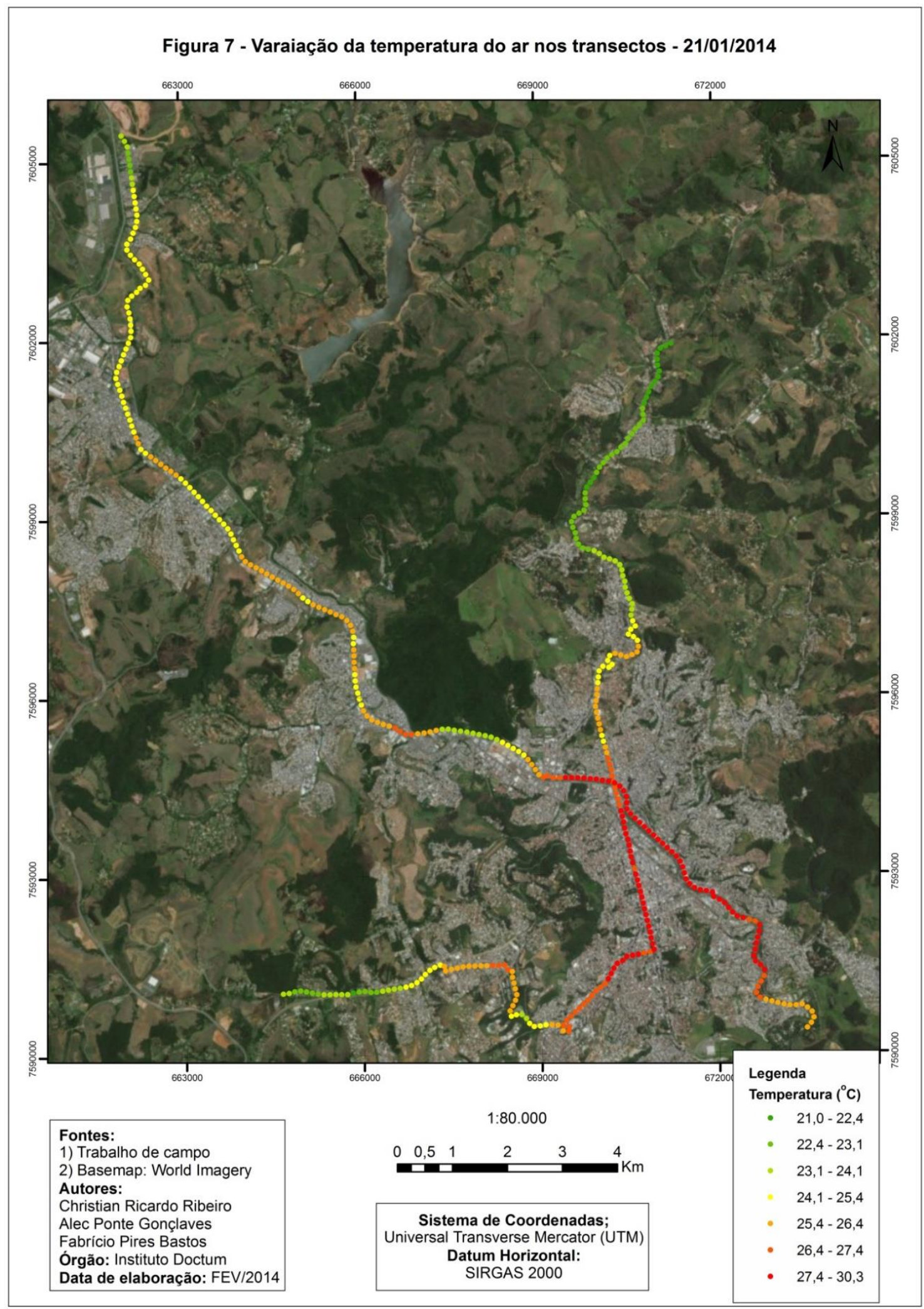

Figura 7 - Variação da temperatura do ar nos transectos - 21/01/2014. 
Ribeiro, C. R.; Gonçalves, A. P.; Bastos, F. P.

ILHAS DE CALOR URBANAS E CONFORTO TÉRMICO HUMANO EM CIDADES DE PORTE MÉDIO: ESTUDO APLICADO EM JUIZ DE FORA (MG)

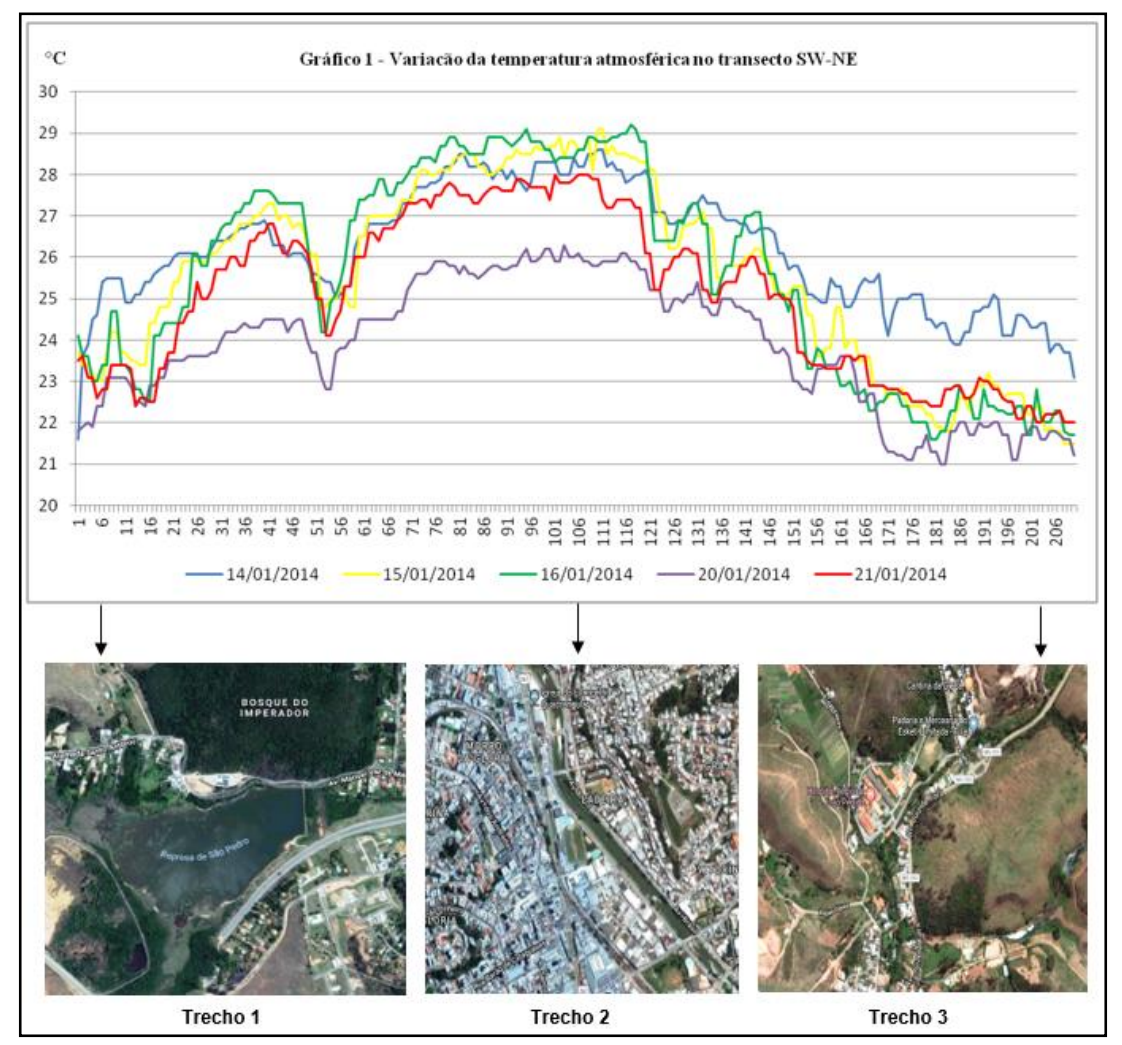

Figura 8 - Variação da temperatura atmosférica no transecto SW - NE.

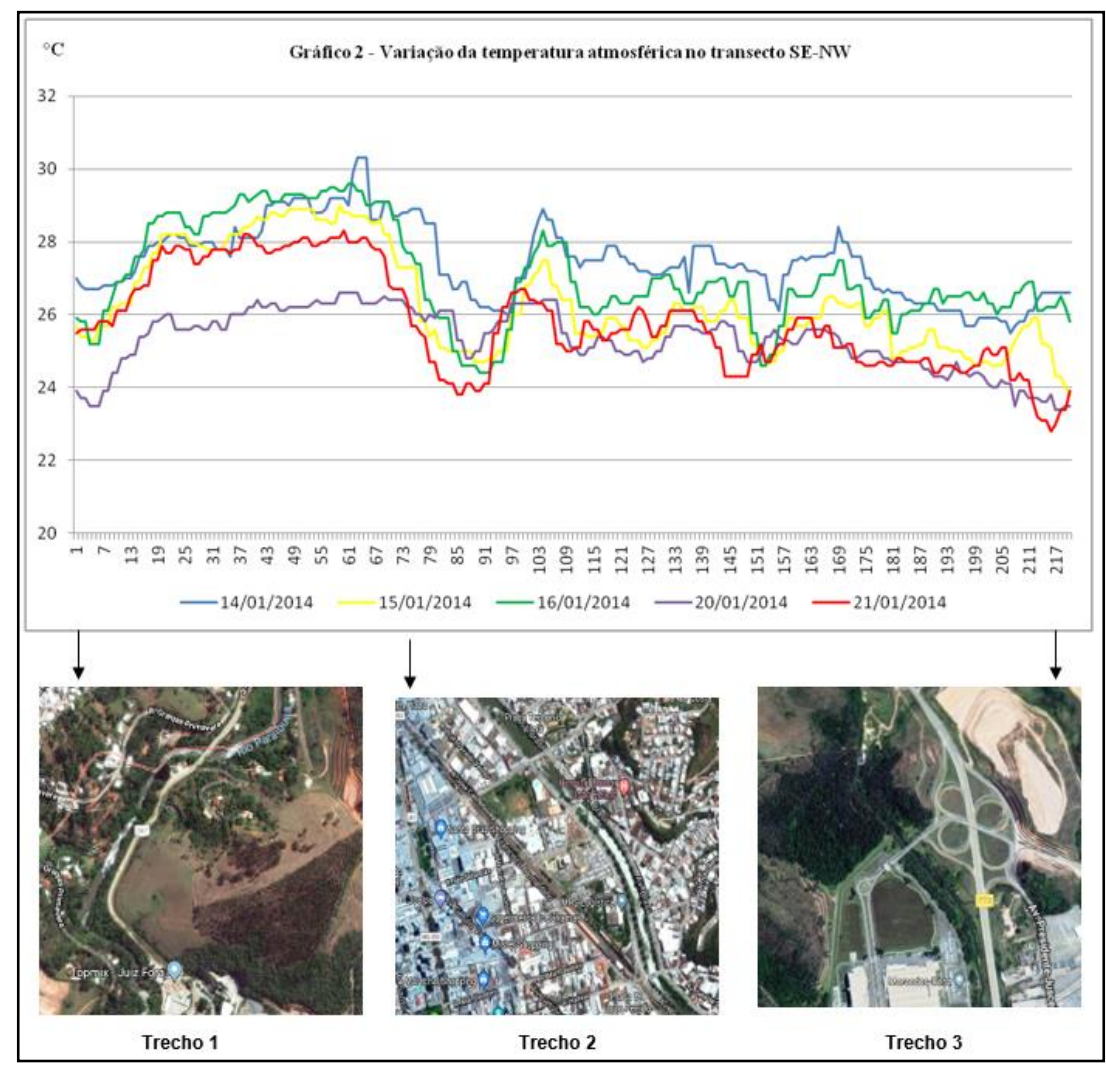

Figura 9 - Variação da temperatura atmosférica no transecto SW - NE. 
Ribeiro, C. R.; Gonçalves, A. P.; Bastos, F. P.

\section{ILHAS DE CALOR URBANAS E CONFORTO TÉRMICO HUMANO EM CIDADES DE PORTE MÉDIO: ESTUDO APLICADO EM JUIZ DE FORA (MG)}

Ao analisarem-se os dois transectos em conjunto, verifica-se que o centro da cidade é a área de maior aquecimento nos dois percursos. O transecto sudoeste-nordeste apresenta as ilhas de calor de maior intensidade, o que denota a influência exercida pelo fator altimétrico nas diferenças de temperatura registradas.

Os dados de temperatura e de umidade relativa do ar coletados nos transectos móveis realizados nos dias 13, 14, 15, 20 e 21/01/2014 foram utilizados para a avaliação do conforto térmico humano em Juiz de Fora através da aplicação do Índice de Desconforto (ID) e da Temperatura Efetiva (TE). A seguir, tem-se a análise dos resultados obtidos com a aplicação dos índices.

O dia 13/01/2014 apresentou, no transecto sudeste-noroeste, as maiores temperaturas máximas e mínimas entre os cinco dias analisados. A amplitude térmica do transecto nesse dia foi de $4,8^{\circ} \mathrm{C}$ e a amplitude higrométrica foi igual a $21 \%$. 0 trecho 1 (pontos 1 a 20) dividiu-se em dois segmentos em termos de zona de conforto: a primeira metade como "confortável" e a segunda como "ligeiramente quente". Esse padrão de distribuição é o mesmo para a Temperatura Efetiva e para o Índice de Desconforto. 0 trecho 2 (área central da cidade, entre os pontos 20 e 80 ) é totalmente caracterizado como "ligeiramente quente" nos dois índices adotados, o que reflete a influência dos condicionantes geoecológicos e geourbanos. O trecho 3 divide-se em três segmentos nos dois índices analisados: "confortável" nas proximidades da Mata do Krambeck (pontos 80 a 100), "ligeiramente quente" entre os pontos 100 e 175 e novamente "confortável" no último segmento (pontos 175 a 220).

Já em relação ao transecto sudoestenordeste, foi registrado nesse dia uma elevada amplitude térmica $\left(7,0^{\circ} \mathrm{C}\right)$. A zona de conforto "confortável" predominou em quase todo o trecho 1 nos dois índices analisados, o que se explica pela importante atuação dos condicionantes geoecológicos na definição do perfil térmico e higrométrico e, consequentemente, do conforto térmico humano. $\mathrm{O}$ trecho 2 dividiu-se em "ligeiramente quente" na área mais próxima ao centro da cidade (pontos 75 a 120) e "confortável" (pontos 75 a 155) no segmento final devido à diferenciação dos condicionantes geoecológicos e geourbanos, nos dois índices analisados. Expressando uma continuidade em relação ao segmento final do trecho 2 , o trecho 3 enquadra-se totalmente na zona de conforto "confortável" nos dois índices analisados.

No dia 14/01/2014 o transecto sudestenoroeste apresentou uma amplitude térmica de $5,2^{\circ} \mathrm{C}$. O trecho 1 caracterizou-se predominantemente como "confortável", o trecho 2 como "ligeiramente quente" e o trecho 3 como "confortável" em toda sua extensão, nos dois índices analisados. No transecto sudoestenordeste este dia apresentou, juntamente com o dia 15/01/2014, a maior amplitude térmica dentre os dias analisados $\left(7,6^{\circ} \mathrm{C}\right)$. $\mathrm{O}$ trecho 1 caracterizou-se predominantemente como "confortável" (com ocorrências de "ligeiramente fresco"), o trecho 2 como "ligeiramente quente" no primeiro segmento (pontos 80 a 120) e "confortável" no segundo segmento (pontos 120 a 155) e o trecho 3 como "confortável" (exprimindo uma continuidade em relação ao segmento final do trecho 2 ). Esse padrão verificou-se nos dois índices analisados. Já no dia 15/01/2014 o transecto sudestenoroeste apresentou uma amplitude térmica igual àquela registrada no dia anterior $\left(5,2^{\circ} \mathrm{C}\right) \mathrm{e}$ uma amplitude higrométrica de $26 \%$. Foi classificado como "confortável" no trecho 1 nos dois índices analisados. 0 trecho 2 dividiu-se em três segmentos sequenciais: "confortável" entre os pontos 20 e 35; entre os pontos 35 e 70, "ligeiramente quente" para a Temperatura Efetiva e "ligeiramente quente" e "confortável" para o Índice de Desconforto; e "confortável" no segmento final.

O trecho 3 , em continuidade à parte final do trecho 2, caracterizou-se como "confortável" na totalidade de sua extensão, para os dois índices analisados. Já o transecto 
Ribeiro, C. R.; Gonçalves, A. P.; Bastos, F. P.

\section{ILHAS DE CALOR URBANAS E CONFORTO TÉRMICO HUMANO EM CIDADES DE PORTE MÉDIO: ESTUDO APLICADO EM JUIZ DE FORA (MG)}

sudoeste-nordeste apresentou elevada amplitude térmica $\left(7,6^{\circ} \mathrm{C}\right)$, como no dia anterior, e a maior amplitude higrométrica do transecto entre os cinco dias analisados (34\%). O trecho 1, diferentemente dos dois dias anteriores, dividiuse em dois segmentos: "ligeiramente fresco" entre os pontos 1 e 15 e "confortável" entre os pontos 20 e 80 , com pequenas variações entre os dois índices analisados. 0 trecho 2 (pontos 80 a 155) foi classificado como "confortável" em praticamente toda a sua totalidade e o trecho 3 (pontos 155 a 210) foi classificado em toda a sua extensão como "ligeiramente fresco", nos dois índices analisados.

No quarto dia analisado, 20/01/2014, foram registradas, no transecto sudestenoroeste, a menor temperatura máxima $\left(26,6^{\circ} \mathrm{C}\right)$, a menor amplitude térmica $\left(3,2^{\circ} \mathrm{C}\right)$ e a menor amplitude higrométrica (16\%) entre os cinco dias analisados. Consequentemente, verificou-se a ocorrência de um padrão de conforto térmico substancialmente diferente em relação aos dias anteriores, pois o transecto (trechos 1, 2 e 3, ou seja, pontos 1 a 220) foi totalmente enquadrado como "confortável" tanto para a Temperatura Efetiva como para o Índice de Desconforto. Já no transecto sudoestenordeste foram registradas a menor temperatura máxima $\left(26,3^{\circ} \mathrm{C}\right)$, a menor temperatura mínima $\left(21^{\circ} \mathrm{C}\right)$, a menor amplitude térmica $\left(5,3^{\circ} \mathrm{C}\right)$ e a maior umidade relativa do ar (64\%) entre os cinco dias analisados. O trecho 1 dividiu-se em "ligeiramente fresco" no segmento inicial (pontos 1 a 20) e "confortável" no segundo segmento (pontos 20 a 80 ) nos dois índices analisados. 0 trecho 2 caracterizou-se como "confortável" em sua quase totalidade e o trecho 3 como "ligeiramente fresco" também em sua quase totalidade nos dois índices analisados.

Finalmente, no último dia analisado, 21/01/2014, o transecto sudeste-noroeste apresentou a menor temperatura mínima $\left(22,8^{\circ} \mathrm{C}\right)$, a maior amplitude térmica $\left(5,5^{\circ} \mathrm{C}\right)$ e a maior amplitude higrométrica (29\%) entre os cinco dias analisados. $O$ trecho 1 alternou entre "confortável" (pontos 1 a 14) e "ligeiramente quente" (14 a 20) e o trecho 2 entre "ligeiramente quente" (pontos 20 e 70) e "confortável" (pontos 70 a 80) nos dois índices analisados.

O trecho 3 enquadrou-se como "confortável" em quase a sua totalidade nos dois índices analisados. Por sua vez, o transecto sudoeste-nordeste apresentou uma amplitude térmica de $6,0^{\circ} \mathrm{C}$ e uma amplitude higrométrica de $31 \%$. O trecho 1 foi classificado predominantemente como "confortável", com pequenas ocorrências de "ligeiramente fresco", nos dois índices analisados. O trecho 2 foi classificado predominantemente como "confortável", com pequenas ocorrências de "ligeiramente quente", nos dois índices analisados. O trecho 3 enquadrou-se como "confortável" em seu segmento inicial (pontos 155 a 175), "ligeiramente fresco" e "confortável" em seu segmento intermediário (pontos 175 e 195) e "ligeiramente fresco" em seu segmento final (pontos 195 a 210), nos dois índices analisados.

\section{Considerações Finais}

A pesquisa demonstrou o maior potencial de aquecimento da área central da cidade em relação às demais, o que se explica pela conjugação de condicionantes geoecológicos e geourbanos atuantes na produção do clima urbano. Em consonância com outros estudos sobre ilhas de calor realizados em cidades de grande e médio porte em todas as regiões do Brasil e com os fundamentos da Climatologia Urbana expressos na literatura específica, observou-se a correlação direta entre fatores como verticalização, densidade demográfica e habitacional, circulação de veículos, morfologia do terreno e cobertura vegetal arbórea com a variação espacial da temperatura e da umidade relativa do ar, levando à formação de ilhas de calor de forte ou até mesmo muito forte intensidade.

Além da importância dos transectos móveis como ferramentas eficazes para o desenvolvimento de estudos em Climatologia Urbana, como demonstrado neste trabalho, 


\section{ILHAS DE CALOR URBANAS E CONFORTO TÉRMICO HUMANO EM CIDADES DE PORTE MÉDIO: ESTUDO APLICADO EM JUIZ DE FORA (MG)}

deve-se ressaltar também o potencial das pesquisas aplicadas em produzir subsídios à implementação de políticas públicas que visem amenizar os efeitos negativos das altas temperaturas sobre a população, contribuindo assim para a melhoria das condições de conforto térmico nas cidades de porte médio. Nesse sentido, Araújo et al. (2010, p. 92) ressaltam que "a territorialização das condições socioeconômicas da população da cidade exerce uma grande influência no conforto térmico, dadas as limitações de grupos sociais, em desvantagem econômica, em dispor de materiais construtivos adequados".

Os resultados apresentados neste trabalho demonstram também uma forte correlação entre a distribuição espacial das zonas de conforto com o perfil térmico e higrométrico de Juiz de Fora. A área central da cidade é aquela que apresenta o maior potencial de aquecimento, tendo sido predominantemente enquadrada como uma zona de conforto que alternou entre "confortável" e "ligeiramente quente" nos dois transectos e durante os cinco dias analisados (com maior ocorrência de "ligeiramente quente" no transecto sudeste-noroeste).

A distribuição espacial do conforto térmico humano em Juiz de Fora não apresentou diferenças importantes em relação à aplicação dos dois índices selecionados: Temperatura Efetiva e Índice de Desconforto. As diferenças foram pouco significativas e bastante pontuais, estando ambos baseados na influência da temperatura e da umidade relativa do ar sobre o conforto térmico do homem. Esses índices constituem uma importante ferramenta para a o estudo do conforto térmico nas cidades brasileiras, pois trabalham com variáveis em número reduzido e de fácil obtenção.

Tendo-se em vista a forte correlação das condições de conforto térmico com vários aspectos da vida humana, especialmente a saúde, deve-se ressaltar a importância da realização de estudos mais detalhados a fim de subsidiar a implementação de medidas e de políticas de planejamento ambiental urbano que levem à transformação de ambientes de desconforto térmico em áreas mais agradáveis às populações lá residentes. A pesquisa constitui, assim, uma abordagem preliminar do problema do conforto térmico em Juiz de Fora, ressaltando a importância da Climatologia Aplicada como campo de estudo que se preocupa com a aplicação do conhecimento e dos princípios climatológicos na solução de problemas práticos que afetam a humanidade.

Destaca-se, finalmente, a contribuição deste estudo para a compreensão do Sistema Clima Urbano, especialmente do Subsistema Termodinâmico, em cidades de porte médio no Brasil. Ainda que a produção científica inicial nesse campo do conhecimento tenha ficado restrita às metrópoles e cidades de grande porte, nos últimos anos cresceu de forma significativa o número de estudos preocupados com essa problemática em cidades de médio porte e mesmo em cidades de pequeno porte, nas quais já se verifica também os impactos provocados pelo processo de urbanização nos elementos climáticos, especialmente na temperatura do ar.

Gartland (2010) elenca uma série de medidas que podem contribuir para a transformação de ambientes caracterizados pelas ilhas de calor urbanas em "comunidades frescas", gerando uma série de benefícios para a população. Espera-se que o poder público, de posse dos resultados produzidos pelos estudos aplicados em Climatologia, possa efetivamente incorporá-los às políticas públicas de planejamento ambiental urbano.

Através de medidas relativamente simples e exequíveis, como o planejamento da localização e da distribuição das áreas verdes, a proteção das edificações contra a incidência direta dos raios solares (especialmente no final da tarde) e a utilização de materiais construtivos adequados (inclusive nos telhados), é possível contribuir de maneira significativa para a melhoria do conforto térmico da população residente nas áreas de maior aquecimento das cidades brasileiras, em sua grande maioria caracterizadas pelas condições de tropicalidade. 
Ribeiro, C. R.; Gonçalves, A. P.; Bastos, F. P.

\section{ILHAS DE CALOR URBANAS E CONFORTO TÉRMICO HUMANO EM CIDADES DE PORTE MÉDIO: ESTUDO APLICADO EM JUIZ DE FORA (MG)}

\section{REFERÊNCIAS}

AMORIM, M. C. de C. T. Ilhas de calor em Birigui/SP. In: Revista Brasileira de Climatologia. Rio de Janeiro: Associação Brasileira de Climatologia, 2005a, dez., vol. 01, n. ${ }^{\circ} 01$, p. 121-130.

Intensidade e forma da ilha de calor urbana em Presidente Prudente/SP: episódios de inverno. In: Geosul. Florianópolis: Universidade Federal de Santa Catarina, 2005b, jan./jun., vol. 20, n. ${ }^{\circ} 39$, p. 65-82.

AMORIM, M. C. de C. T.; SANT'ANNA NETO, J. L.; DUBREUIL, V. Estrutura térmica identificada por transectos móveis e canal termal do Landsat 7 em cidade tropical. In: Revista Geografía Norte Grande. Santiago: Pontificia Universidad Católica de Chile, 2009, n. ${ }^{\circ} 43$, p. 65-80.

ARAÚJO, A. P. et al. Ensaio metodológico sobre a utilização de transectos móveis no período diurno em Presidente Prudente - SP. In: Formação. Presidente Prudente: Universidade Estadual Paulista, 2010, n. ${ }^{\circ}$ 17, vol. 1, p. 77-95.

AYOADE, J. O. Introdução à Climatologia para os trópicos. $8 .^{\mathrm{a}}$ ed. Rio de Janeiro: Bertrand Brasil, 2002.

FANGER, P. O. Thermal comfort. New York: McGraw-Hill, 1972.

GARCÍA, F. F. Manual de Climatología Aplicada: clima, médio y planificación. Madrid: Sintesis, 1996.

GARTLAND, L. Ilhas de calor: como mitigar zonas de calor em áreas urbanas. São Paulo: Oficina de Textos, 2010.

GILES, D. B.; BALAFOUTS, C.; MAHERAS, P. Too hot for comfort: the heatwaves in Greece in 1987 and 1988. In: International Journal of Biometeorology, 1990, ago., vol. 34, n. ${ }^{\circ} 02$, p. 98-104.

INSTITUTO BRASILEIRO DE GEOGRAFIA E ESTATÍ́STICA. Manual técnico de uso da terra. 2. a ed. Rio de Janeiro: Instituto Brasileiro de Geografia e Estatística, 2006.
LOMBARDO, M. A. Ilha de calor nas metrópoles: o exemplo de São Paulo. São Paulo: Hucitec, 1985.

MAIA, J. A.; GONÇALVES, F. L. T. Uma análise do conforto térmico e suas relações meteorotrópicas na cidade de São Paulo. In: CONGRESSO BRASILEIRO DE METEOROLOGIA, 12, 2002, Foz do Iguaçu. Anais eletrônicos... Foz do Iguaçu: Sociedade Brasileira de Meteorologia, 2002, p. 305-314.

MENDONÇA, F. de A. O clima e o planejamento urbano de cidades de porte médio e pequeno: proposição metodológica para estudo e sua aplicação à cidade de Londrina/PR. 1994. 335 f Tese (Doutorado em Geografia Física) Faculdade de Filosofia, Letras e Ciências Humanas, Universidade de São Paulo, São Paulo, 1994.

O estudo do clima urbano no Brasil. In: MONTEIRO, C. A. de F.; MENDONÇA, F. (Org.). Clima Urbano. 2. ${ }^{\text {a }}$ ed. São Paulo: Contexto, 2011, p. 175-192.

MISSENARD, A. L'homme et le climat. Paris: Librairie Plon, 1937.

MONTEIRO, C. A. de F. Teoria e Clima Urbano. São Paulo: Instituto de Geociências da Universidade de São Paulo, 1976. (Série Teses e Monografias).

Teoria e clima urbano: um projeto e seus caminhos. In: MONTEIRO, C. A. de F.; MENDONÇA, F. (Org.). Clima urbano. 2. ${ }^{\text {a }}$ ed. São Paulo: Contexto, 2001, p. 09-67.

ONO, H.-S. P.; KAWAMURA, T. Sensible climates in monsoon Asia. In: International Journal of Biometeorology, 1991, jun., vol. 35, n. ${ }^{\circ} 01$, p. 39 $-47$.

NOVO, E. M. L. de M. Sensoriamento Remoto: princípios e aplicações. 2. a ed. São Paulo: Edgard Blücher, 1995.

ORTIZ, G. F. O clima urbano de Cândido Mota: análise do perfil térmico e higrométrico em episódios de verão. 2012. 162 f. Dissertação (Mestrado em Geografia) - Faculdade de Ciências e Tecnologia, Universidade Estadual Paulista, Presidente Prudente, 2012. 


\section{ILHAS DE CALOR URBANAS E CONFORTO TÉRMICO HUMANO EM CIDADES DE PORTE MÉDIO: ESTUDO APLICADO EM JUIZ DE FORA (MG)}

SANTOS, F. M. de M.; NOGUEIRA, M. C. de J. A. Análise da influência da ocupação do solo na variação termo-higrométrica por meio de transectos noturnos em Cuiabá - MT. In: Caminhos de Geografia. Uberlândia: Universidade Federal de Uberlândia, 2012, mar., vol. 13, n. $^{\circ} 41$, p. $187-194$.

SOUZA, D. M. de; NERY, J. T. O conforto térmico na perspectiva da Climatologia Geográfica. In: Geografia. Londrina: Universidade Estadual de Londrina, 2012, mai./ago., vol. 21, n. ${ }^{\circ} 02$, p. 6583.

THOM, E. C. The discomfort index. Boston: Weatherwise, 1959, vol. 12, p. 57-60.

VIANA, S. S. M.; AMORIM, M. C. de C. T. O clima urbano em Teodoro Sampaio/SP: episódios de verão. In: Revista Brasileira de Climatologia. Rio de Janeiro: Associação Brasileira de Climatologia, 2009, set., vol. 05, p. 41-54.

UGEDA JÚNIOR, J. C.; AMORIM, M. C. de C. T. Estudo do clima urbano de Jales - SP através do transecto móvel. In: Geonorte. Amazonas: Universidade Federal do Amazonas, 2012, edição especial 2, n. ${ }^{\circ}$ 5, vol. 2, p. 365-377. 